CUPAUAM. 19-1992, 289-317

\title{
NUEVAS EVIDENCIAS DE ONUBA
}

\author{
Jesus Fernandez Jurado \\ Pilar Rufete TOMICO \\ Carmen Garcia SanZ \\ SECCION DE ARQUEOLOGIA DE \\ la Diputacion de Huelva
}

\section{Resumen}

Las evidencias romanas halladas en Huelva, la vieja Onuba, se reducían a excavaciones realizadas en los años setenta en necrópolis y factorías de salazones. El presente artículo ofrece nuevos datos sobre el hasta hoy desconocido poblado y nos permiten establecer tres etapas: la importante segunda mitad del siglo I, el vacio existente por el momento durante el siglo II y la decadencia de los siglos III y IV.

\section{Summary}

The Romans evidences found in Huelva, the old Onuba, were reduced to excavations executed on the seventiesh at necropolis and fish salties factories. This article offers new informations about this village, unknown until this moment, and this permites us to stablish three periods: the important second half of the first century; the existing gap withen of the IInd century at the moment; and the decadence of the IIIrd and IVth centuries.

Mucho se ha escrito y desde hace tiempo, respecto de la identificación de ONUBA con HUELVA; pero ni la antigüedad de los escritos, ni éstos mismos, encontraban una real y fehaciente corroboración arqueológica, siendo la ausencia de ésta causa y razón de no pocas controversias sobre si era o no cierta la asimilación antes citada, así como que sean más los textos dedicados a este problema que los resultantes de la investigación arqueológica propiamente dicha.

De otra parte, la escasez de datos arqueológicos parecía justificarse por la continuada ocupación del mismo territorio a través de los siglos, con lo que ello implica de destrucción y modificación estratigráfica, circunstancia a la que se añadía la intensa y profunda transformación urbanística que, desde mediados de la década de los sesenta, venía produciéndose en Huelva, lo que repercutía negativamente en los restos arqueológicos. 
No obstante, esta realidad comenzó a transformarse en la década de los setenta, merced a la labor excavatoria llevada a cabo por el Museo de Huelva, tarea que ya en la de los ochenta pasó a ser desarrollada por la Sección de Arqueología de la Diputación de Huelva.

Esta investigación es la que pretendemos reflejar en las páginas que siguen, sintetizando primero las actuaciones y resultados obtenidos por M. del Amo (1976); y presentando, como avance, los por nosotros obtenidos en los últimos años.

En definitiva, consideramos que la investigación hasta ahora desarrollada permite despejar dudas sobre la ubicación de ONUBA y hacer una mejor y más correcta valoración de su realidad.

\section{DECADA DE LOS SETENTA}

Hasta la década de los ochenta, los datos de época romana obtenidos en Huelva, fueron el resultado de intervenciones de urgencia tras las tareas de remoción de tierras para la realización de edificios de nueva planta. Este hecho ha motivado la escasez de evidencias arqueológicas, debidamente documentadas, que sirvieran para realizar un estudio en profundidad del período de ocupación romana en esta ciudad; sin embargo, es significativa la presencia entre éstos de dos tipos de restos (fig. 1): unos, los correspondientes a factorías de salazones (Amo, 1976, 21-80); y otros, a las necrópolis (Amo, 1976, 81-107), sin que hasta ese momento se hubieran documentado elementos constructivos pertenecientes al poblado.

En la actualidad y tras las excavaciones por nosotros realizadas, el panorama se ha ampliado gracias a la documentación de zonas de hábitat (fig. 1).

\section{Factorías}

Las factorías, encontradas en las calles Palos 21 y Millán Astray 4-8 (hoy Tres de Agosto)(fig. 1), ocupan una superficie rectangular delimitada por una estructura constructiva realizada con mampuestos de pizarra, de mayor anchura que los muros interiores que distribuyen este espacio. Dicha construcción estaba formada por los mampuestos citados y sobre ellos una superestructura de ladrillos, quedando embutidas en el suelo las piletas.

\section{Factoria de Palos 21}

La distribución interna en esta factoría viene determinada por la diferenciación de la misma en tres sectores (Amo, 1976, 25-43) (fig. 2):

- El sector Sur estaba ocupado por dos piletas similares a las anteriores y un amplio espacio recubierto con opus.

- El sector central también estaba recubierto con opus signinum y tenía un ligero desnivel hacia el Oeste.

- El sector norte se encontraba separado del anterior por un muro, al parecer construido en un momento posterior a las piletas y que se sobreelevó con tégulas y ladrillos, realizándose con peor técnica constructiva que las estructuras anteriores.

Es difícil precisar a qué periodo cronológico corresponderían estas reformas, ya que no se documentó una estratigrafía definida y tan sólo se puede obtener una cronología aproximada por el conjunto de materiales que se presenta en la memoria. Así, de acuerdo con el autor de la investigación, el nivel de base anterior a la construcción de las piletas correspondería a la prime- 
ra mitad del siglo I d.C., por la presencia de cerámica sudgálica, paredes finas con barbotina y la ausencia de sigillata hispánica (Amo, 1976, 30-31). Ya en el interior de estas estancias sí aparece la sigillata hispánica y por la ausencia de cerámica clara tipo B, el autor da una cronología para el abandono de la zona de fines del II d.C. (Amo, 1976, 34).

\section{Factoria de Millán Astray 4-8 (hoy Tres de Agosto).}

En este caso se pudo documentar una factoría de salazones de las mismas características que la antes descrita (fig. 2), aunque sin que se obtuviera tampoco una clara secuencia estratigráfica (fig. 3).

Las seis piletas estaban realizadas con mampuestos de pizarra cubiertos por el interior con una capa de mortero que en la base tenía la característica moldura de media caña. Sobre estas piletas, en un momento posterior, se construyó una habitación rectangular, realizada con la misma técnica constructiva que el resto de las estructuras, pero que alcanzaba mayor profundidad que las piletas. Este hecho hizo pensar que se tratara de un aljibe, más aún cuando en los muros Este y Oeste se observaba la tendencia hacia una cubierta abovedada y en el suelo presentaba una concavidad de 0'80 m. de diámetro y 0'20 m. de profundidad.

Dicha cisterna variaba la estructura interna de la factoría, dada la necesidad de agua en la misma, por lo que se rebajó para su construcción el nivel de suelo de las piletas. En su interior aparecieron escasos fragmentos de cerámicas finas, pero que son utilizadas por el autor para establecer como fecha de abandono de la factoría la de fines del III o principios del IV d.C. (Amo, 1976,65 ), ya que entre los materiales se encuentra sigillata clara D, cuya producción, como es sabido, tiene lugar en el siglo IV d.C., junto a sigillatas hispánica, sudgálica, aretina y otras cerámicas comunes. En esta recogida de materiales se realizó un sondeo por debajo de la cisterna, pudiéndose observar la presencia de material, más antiguo y de procedencia púnica, no anterior al 700 a.C. (Amo, 1976, 80); no obstante, ha de indicarse que es escaso y está fuera de contexto estratigráfico.

\section{Necrópolis}

En cuanto a las zonas de enterramiento (fig. 1) su localización y posterior excavación se realizaron en las mismas negativas condiciones expuestas en el caso de las factorías, lo que motivó la pérdida de numerosos datos que pudieran utilizarse en su estudio.

\section{Necrópolis de "La Esperanza" (fig. 1).}

Se pudieron documentar algunas tumbas de incineración constituidas por una urna y un plato a modo de tapadera, sin que se encontraran otros restos del ajuar. Por la tipología de estas urnas se fecharon en la primera mitad del siglo I d.C. (Amo, 1976, 87).

Sin embargo, el hallazgo de dos tumbas más completas permitió conocer más datos acerca de los enterramientos de época romana en Huelva. Dichas tumbas estaban formadas por tégulas dispuestas en doble vertiente y sobre las cenizas se extendía todo el ajuar, que correspondía a la misma cronología dada para los restos de tumbas anteriores.

Esta necrópolis pudo haber perdurado hasta el s. II d.C. (Amo, 1976, 88). 
Necrópolis de la calle Onésimo Redondo (hoy Plácido Bañuelos).

Los enterramientos se encontraban a 3-4 m. por debajo del nivel de la calle y junto a ellos se hallaron materiales más antiguos, procedentes posiblemente de arrastres del cabezo de San Pedro.

Se excavaron 8 tumbas de inhumación, que tenían diferentes técnicas constructivas (fig. 4): tres se realizaron con ladrillos en forma rectangular y tapadas con tégulas dispuestas horizontalmente; otras tres tenían la cubiera a doble vertiente. Junto a éstas existía una fosa excavada en la tierra y cubierta por tégulas horizontales, así como un enterramiento infantil en ánfora.

Los escasos materiales correspondientes a los ajuares parecen fechar esta necrópolis en el s. III d.C., si bien el enterramiento en ánfora podría corresponder a principios del IV d.C, por la tipología cerámica.

En conjunto, parece que la necrópolis fue utilizada desde mediados del siglo III hasta principios del IV d.C. (Amo, 1976, 96-97).

\section{Necrópolis de La Orden}

Situada al norte de la ciudad, corresponde a una necrópolis de inhumación, destruida en gran parte por las máquinas excavadoras.

Hay cuatro tipos de sepulturas (fig. 5):

- Caja rectangular construida con ladrillos dispuestos a soga, con una cubierta de tégulas colocadas en horizontal y sobre éstas otras dispuestas a doble vertiente. El fondo no siempre estaba cubierto con tégulas.

- Otro tipo es similar al anterior, pero sin la cubierta a doble vertiente y en algunas (34, 35 y 36) los muros de la caja están construidos con ladrillos colocados de canto y a soga.

- Fosa excavada en la tierra y cubierta con tégulas a doble vertiente.

- Enterramientos infantiles en ánforas.

Si bien las tumbas recuperadas son 41 , debieron existir algunas más, que fueron destruidas durante la explanación del solar.

Los enterramientos se encontraban orientados en el eje Este-Oeste y no tenían ajuar funerario, salvo la tumba 21 con un jarro que, junto a algunas monedas halladas fuera de las sepulturas, pudieron proporcionar una cronología que va desde principios del siglo IV hasta el V d.C. (Amo, 1976, 107).

Junto a los restos antes descritos, también se localizaron en las cercanías tres hornos de producción cerámica, de los que dos de ellos sólo conservaban la capa de tierra rojiza que constituía la base y el tercero, que mantenía la parte del muro circular que lo delimitaba, estaba realizado con ladrillos y en el centro de dicho espacio se levantaba un tambor, también de ladrillos, revestido con una capa de barro que estaba afectada por la combustión. En la parte Sur del muro existía una abertura y allí conservaba restos de la cubierta, hecha de ladrillo y con tendencia abovedada.

Otros restos aparecidos en un lugar cercano, podrían ser construcciones pertenecientes al poblado que correspondería a la necrópolis antes descrita; sin embargo, no se excavaron y no es posible establecer esta correlación. 


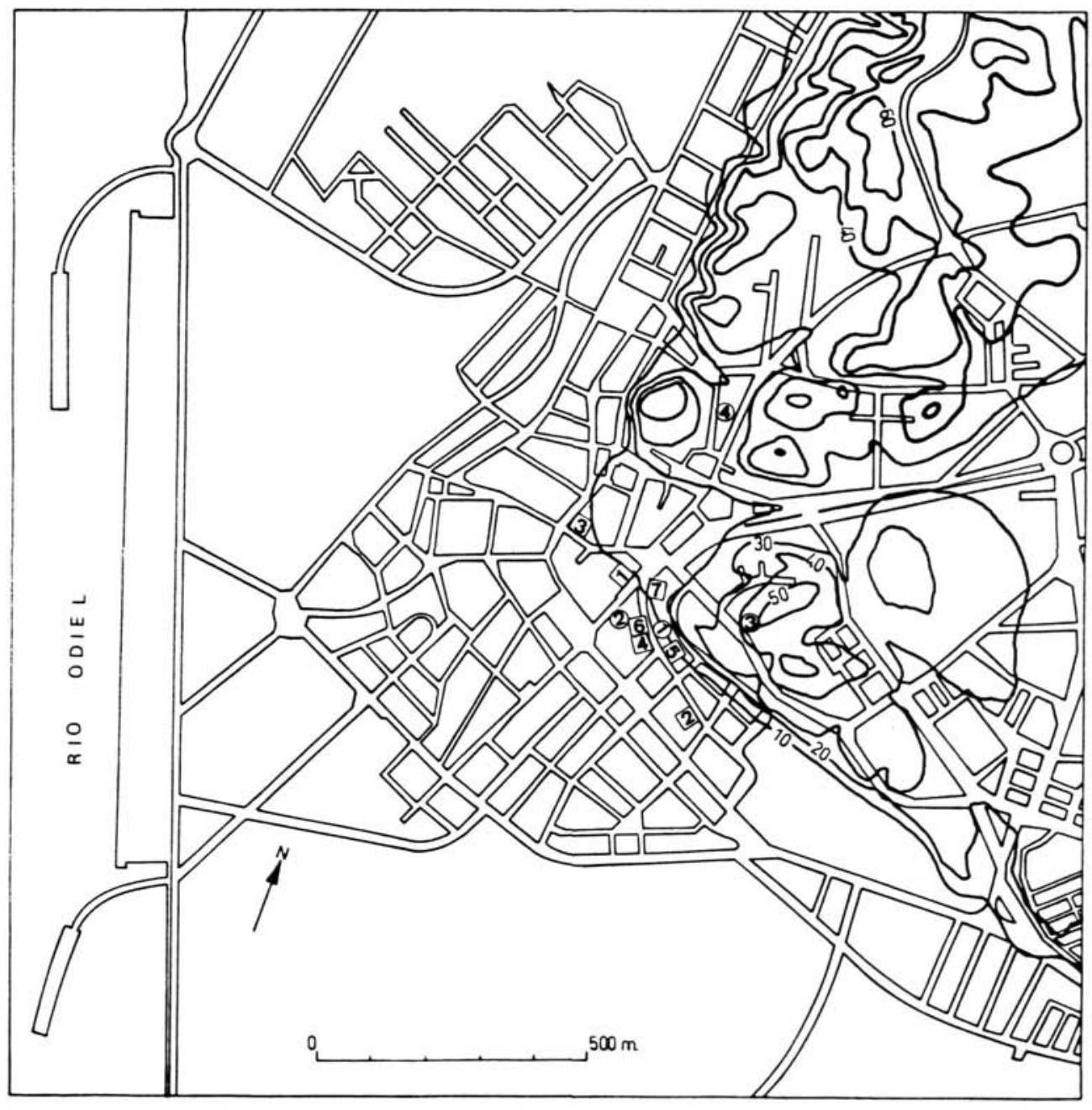

\begin{tabular}{|c|c|}
\hline & DECADA DE LOS OCHENTA \\
\hline 1 & TRES DE AGOSTO, 9-11 \\
\hline 2 & FERNANDO EL CATOLICO, 10 \\
\hline 3 & PUERTO. 12 \\
\hline 4 & PALOS, 12 \\
\hline [5] & PALOS, 23 \\
\hline 6] & PALOS, 10 \\
\hline 7 & PALOS, $1-3$ \\
\hline
\end{tabular}

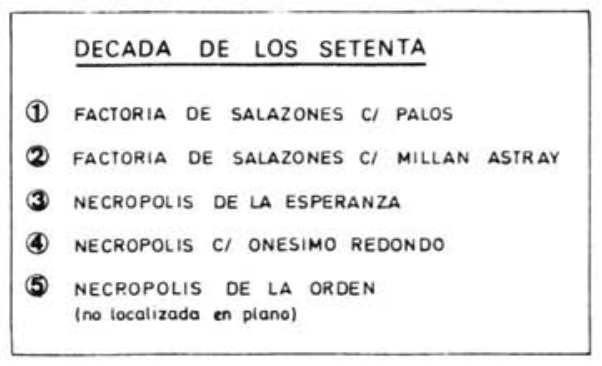

Figura 1. Excavaciones con evidencias romanas en Huelva. 


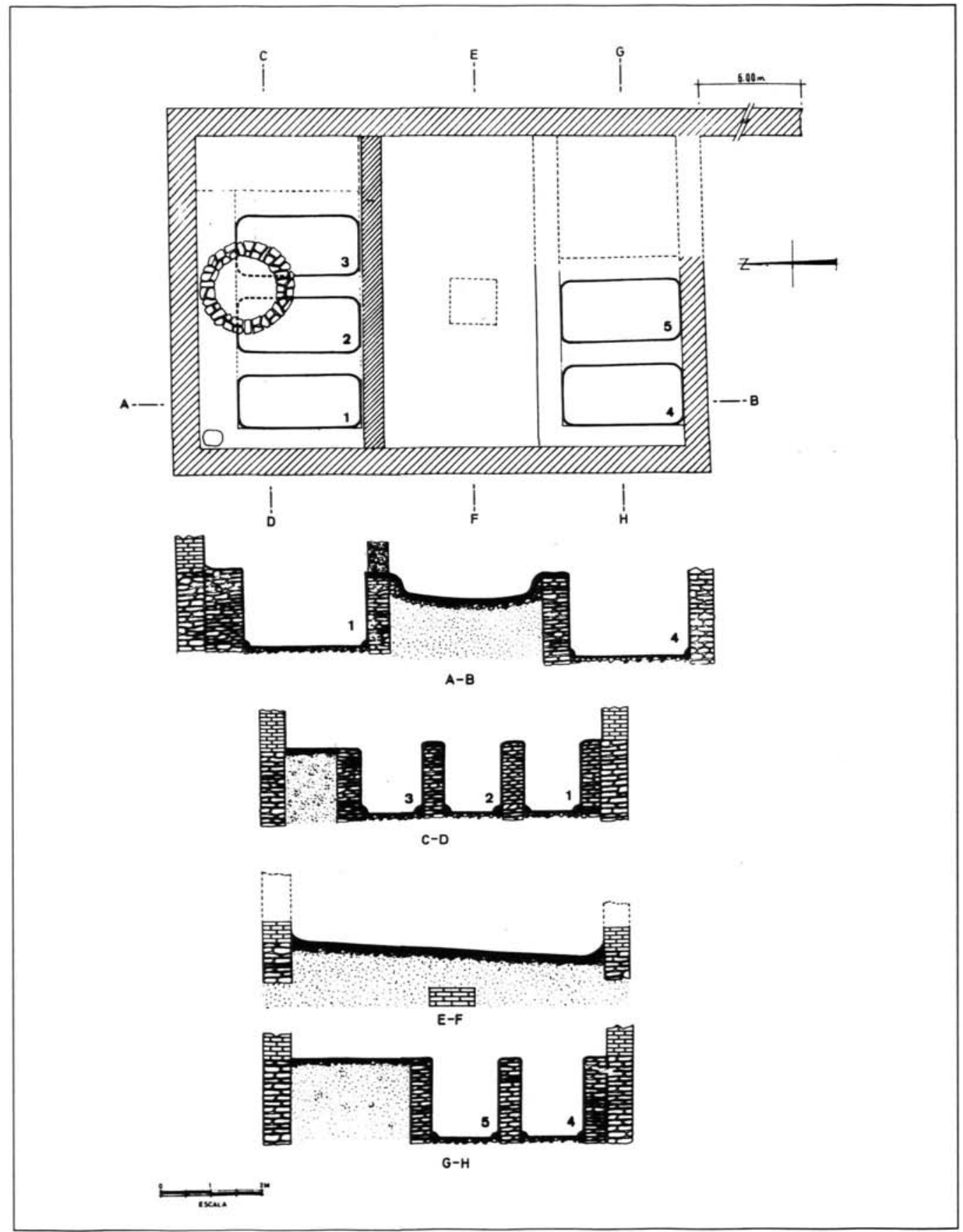

Figura 2. Factoría de salazones de Palos 21 (según Amo, 1976). 


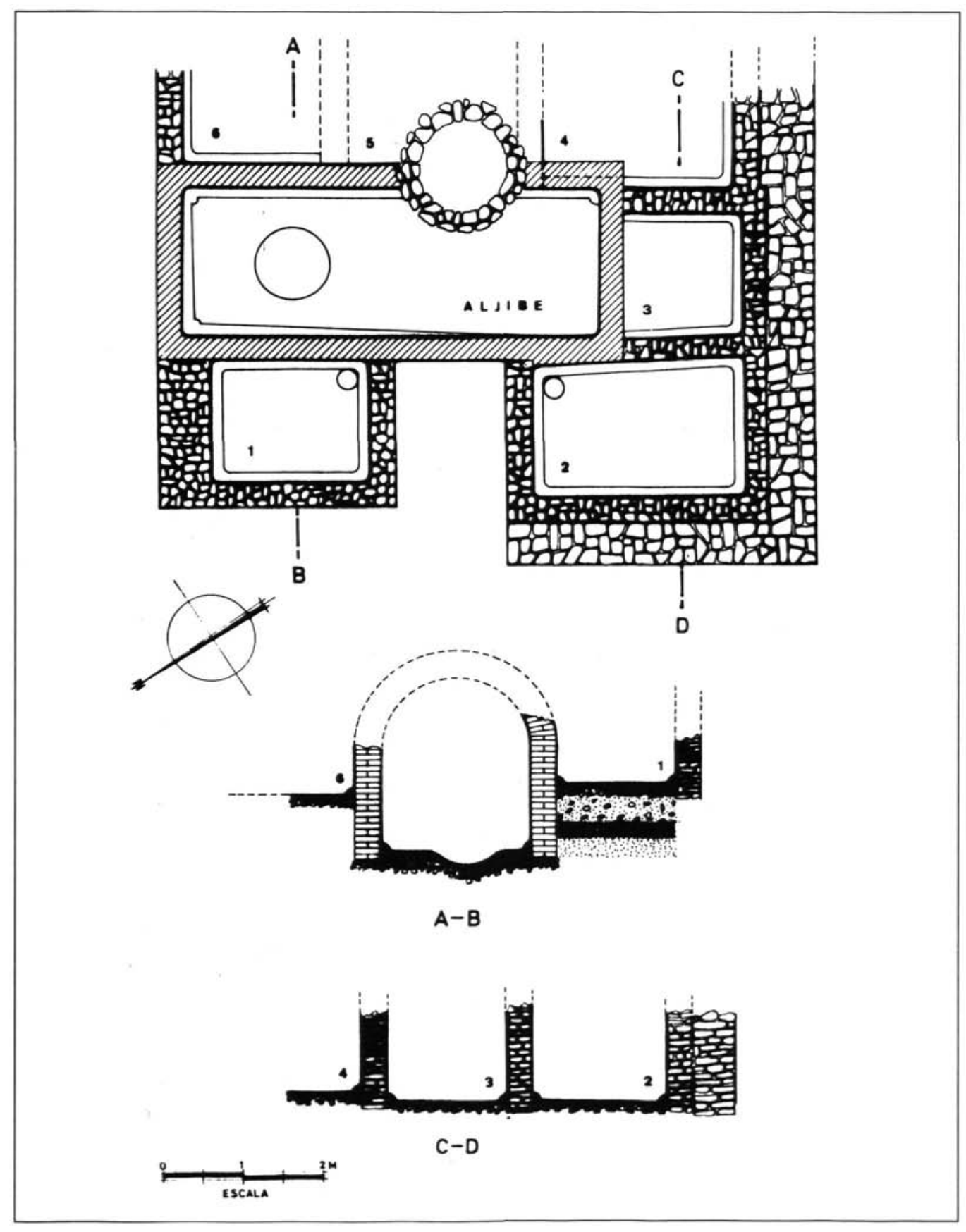

Figura 3. Factoría de salazones de Millán Astray 4-8 (según Amo, 1976). 


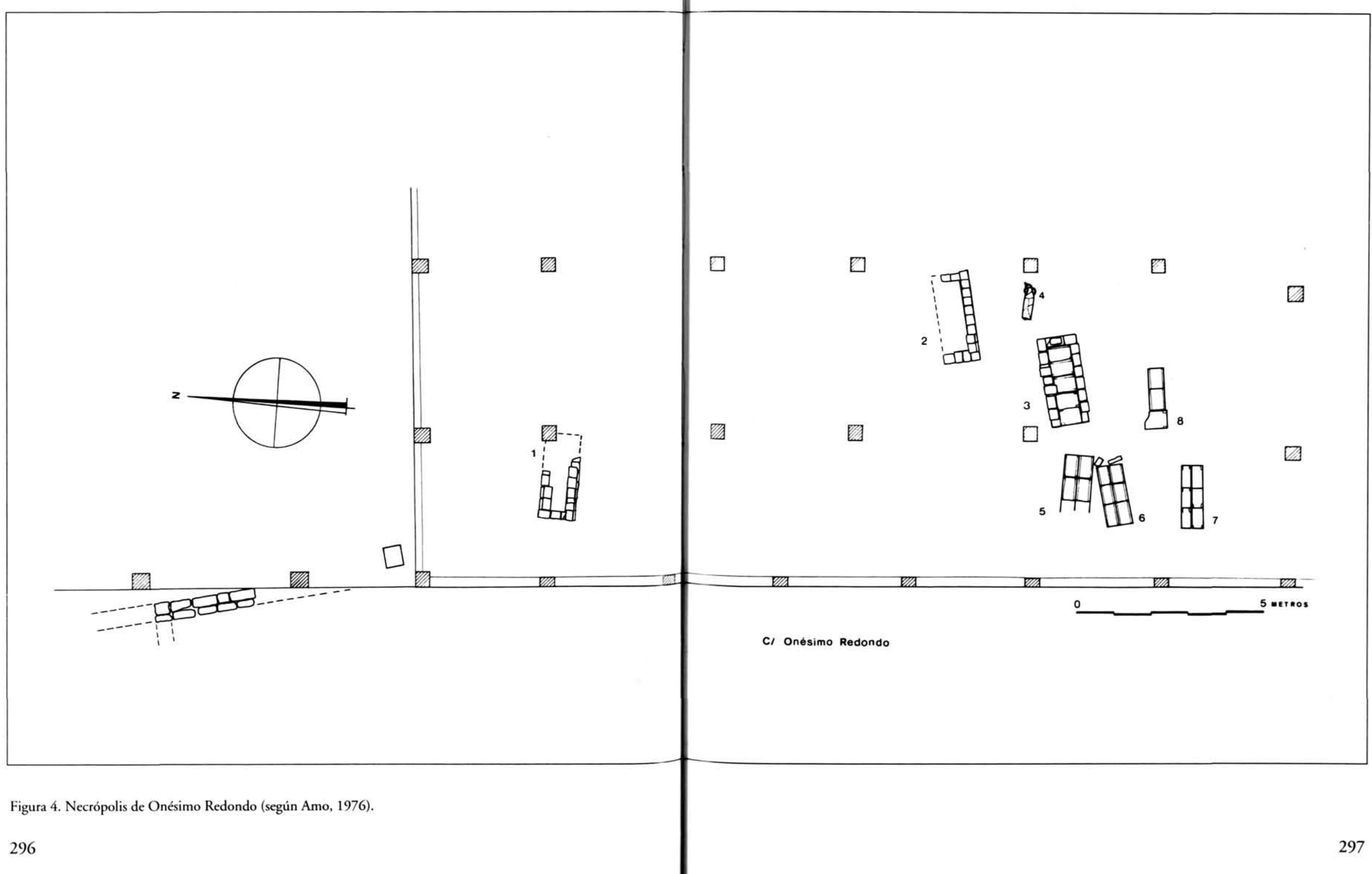




\begin{tabular}{|c|c|}
\hline & 0 \\
\hline
\end{tabular}




\section{DECADA DE LOS OCHENTA}

Desde el año 1982, la Sección de Arqueología de la Diputación Provincial de Huelva se encarga de la investigación arqueológica en el casco urbano de esta ciudad; sin embargo, hasta el año 1988 no habían aparecido en las excavaciones realizadas restos de época romana, realidad que coincide con las excavaciones efectuadas en zonas altas de la ciudad, en las que se encontraron las evidencias romanas que a continuación describimos.

No exponemos aquí valoración alguna de la excavación realizada en Palos 1-3 (fig. 1), por no haberse iniciado aún su estudio, aunque hemos de señalar la presencia en la misma de conducciones de agua, realizadas mediante una canalización de ladrillos y dentro de ellas una estrecha tubería de hierro (fig. 6), de la que sólo se conservaban pequeñísimos fragmentos muy oxidados.

Del mismo modo, hemos de reseñar que en el verano de 1988 realizamos un sondeo en el solar 8-10 de la misma calle Palos, donde pudimos documentar una estratigrafía de época romana que, de forma ininterrumpida, abarcaba el espacio comprendido entre la cota de -1 ' 80 y la de $-4,00 \mathrm{~m}$. Este solar, ya hoy construido, no fue excavado porque el edificio de nueva planta que se levantó en este lugar, se apoya sobre un cimiento de placa de hormigón situada a -1'50 m. y no sobre pilotes; ante este tipo de cimentación, la Delegación Provincial de Cultura consideró oportuno no llevar a cabo excavación alguna y dejar el lugar como reserva arqueológica (1). No obstante, esta falta de datos queda parcialmente compensada con la excavación que hemos realizado en el solar contiguo (Palos 12-Convento de las Agustinas), que más adelante presentamos.

\section{Calle Tres de Agosto 9-11 (antigua Millán Astray)}

En el año 1988 llevamos a cabo la excavación de este solar (fig. 1), donde abrimos un corte de $7^{\prime} 20 \times 5 \mathrm{~m}$. en la zona más al interior del mismo. Dado el carácter de excavación en casco urbano aparecieron restos de pozos modernos, pero que tan sólo afectaban a la capa superficial, no sobrepasando $1 \mathrm{~m}$. de profundidad desde la superficie.

En el ángulo SO del cuadro hallamos, en la cota -1'34 m., una estructura formando ángulo que penetraba en los perfiles Oeste y Sur, delimitando parte de lo que debió ser el interior de una habitación (fig. 7)(2).

Estos muros tenían una anchura de 0'60 m. y conservaban una potencia máxima de 0'40 m. La base estaba constituida por una hilada de pequeñas lajas de pizarra, colocadas verticalmente, que servían de nivelación.

Las siguientes hiladas estaban constituidas por pizarras de mayor tamańo, que sólo se conservaban en el muro que penetraba en el perfil occidental; sin embargo, en la zona más próxima al perfil y por la cara exterior, no se apreciaba tan claramente la hilada inferior formada por pequeñas pizarras, sino que aparecían piedras mayores y no tan verticalmente colocadas.

(1) En el informe por nosotros emitido, tras realizar el sondeo, hacíamos referencia a la realidad expuesta, así como al hallazgo de un trozo de fuste de columna de mármol, de unos $50 \mathrm{cms}$. de largo y algo más de $20 \mathrm{cms}$. de diámetro, así como comunicamos la oportunidad de iniciar excavaciones, lo que no se hizo, como ya ha quedado dicho.

(2) Los muros de esta habitación romana apoyaban directamente sobre los niveles de época protohistórica, lo que viene siendo habitual en todas aquellas excavaciones en que aparecen restos romanos, en la ciudad de Huelva. 


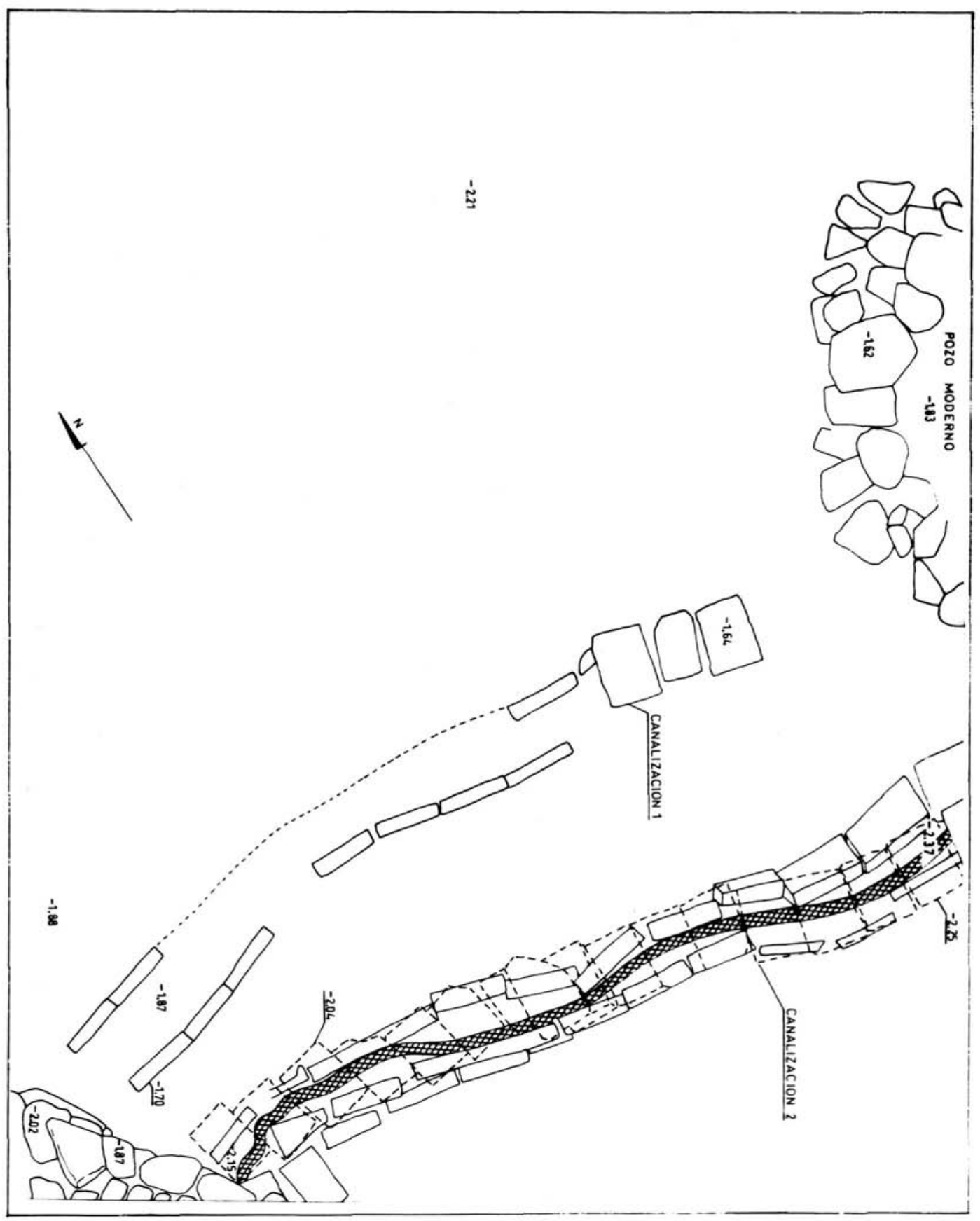

Figura 6. Conducciones de agua de Palos 1-3. 
El otro muro sólo conservaba la hilada inferior y en su zona central las pizarras se habían sustituido, de antiguo, por restos de ladrillos, sobre los que se apoyaba un gran sillar de piedra caliza con tres de sus caras bien escuadradas, mientras que el lado irregular, que daba al interior, se completaba con más trozos de ladrillos.

La cara interna de la construcción conservaba restos de un posible estucado hecho con un suave mortero de cal. En el interior de la habitación se hallaron gran cantidad de tégulas, ladrillos y restos de revoque, conformando un potente estrato que correspondía al derrumbe de la habitación. Al vaciarla no se apreció la existencia de pavimento alguno.

Como elemento cronológico que nos sirva para situar este nivel de habitación, contamos con un fragmento decorado de sigillata sudgálica con relieves, perteneciente a la forma Drag. 37, que se fecha en la segunda mitad del siglo I d.C. (fig. 13, 1)(Beltrán, 1990, 371373).

También hemos de indicar que entre los materiales de superficie y en consecuencia fuera de contexto arqueológico, encontramos un fragmento de sigillata aretina con el sello P. HERTO (fig. 13, 3), fechable entre el 10 a.C. y el 10 d.C. (Poveda y Ribera, 1985, 306, 4), siendo éste el elemento de mayor antigüedad que nosotros hemos constatado en nuestras excavaciones y que viene a acompañar a otros fragmentos de sigillata aretina, también hallados fuera de contexto, procedentes de la factoría excavada en Millán Astray 4-8 (Amo, 1976, 48, 13).

Acompaña a este fragmento otro de sigillata marmorata cercano a la forma Drag. 15/17 (fig. 13, 2)(Beltrán, 1990, 90, 295), lo que corrobora lo revuelto de este nivel superficial.

\section{Calle Fernando el Católico 10}

En el mes de Diciembre de 1988 iniciamos los trabajos arqueológicos en el solar $\mathrm{n}^{\circ} 10$ de esta calle, procediendo para ello a la apertura de un cuadro de 3'20x4'20 m. (figs. 1 y 8).

Bajo una capa de relleno, de algo más de $2 \mathrm{~m}$. de potencia, apareció a -2'30 m. la esquina de una construcción pétrea que conservaba cinco hiladas y una potencia máxima de $0^{\prime} 80 \mathrm{~m}$. Estaba realizada con pizarras de mediano y gran tamaño, con una buena técnica constructiva y rellenos con pequeñas piedras los intersticios. Para reforzar la esquina se utilizaron dos bloques de arenisca de gran tamaño (0'72 $\times 0^{\prime} 30 \times 0^{\prime} 30 \mathrm{~m}$.), ocupando cada uno de ellos la altura de dos hiladas de piedras y dejando una entre ambos. De los dos bloques, al menos el superior parece haber sido reutilizado, ya que presenta por el exterior unos rehundimientos para el ajuste en una construcción anterior. Sobre la última hilada de la construcción había un ladrillo, por lo que no podemos descartar la utilización de este material en la edificación, lo que parece frecuente en otras construcciones romanas que hemos excavado recientemente y que en las páginas que siguen describimos.

Esta construcción corresponde a época romano imperial, sin que podamos precisar por el momento ningún periodo cronológico, ya que en el interior de lo que debió ser esta habitación se encontraron numerosos fragmentos de tégulas, ladrillos y sigillatas hispánicas, materiales con un amplio marco cronológico.

\section{Calle Puerto 12}

En Noviembre de 1989 iniciamos la excavación de este solar de la Calle Puerto (fig. 1), procediéndose a la apertura de un cuadro de $10^{\prime} 5 \times 11 \mathrm{~m}$. (fig. 9)(3). 


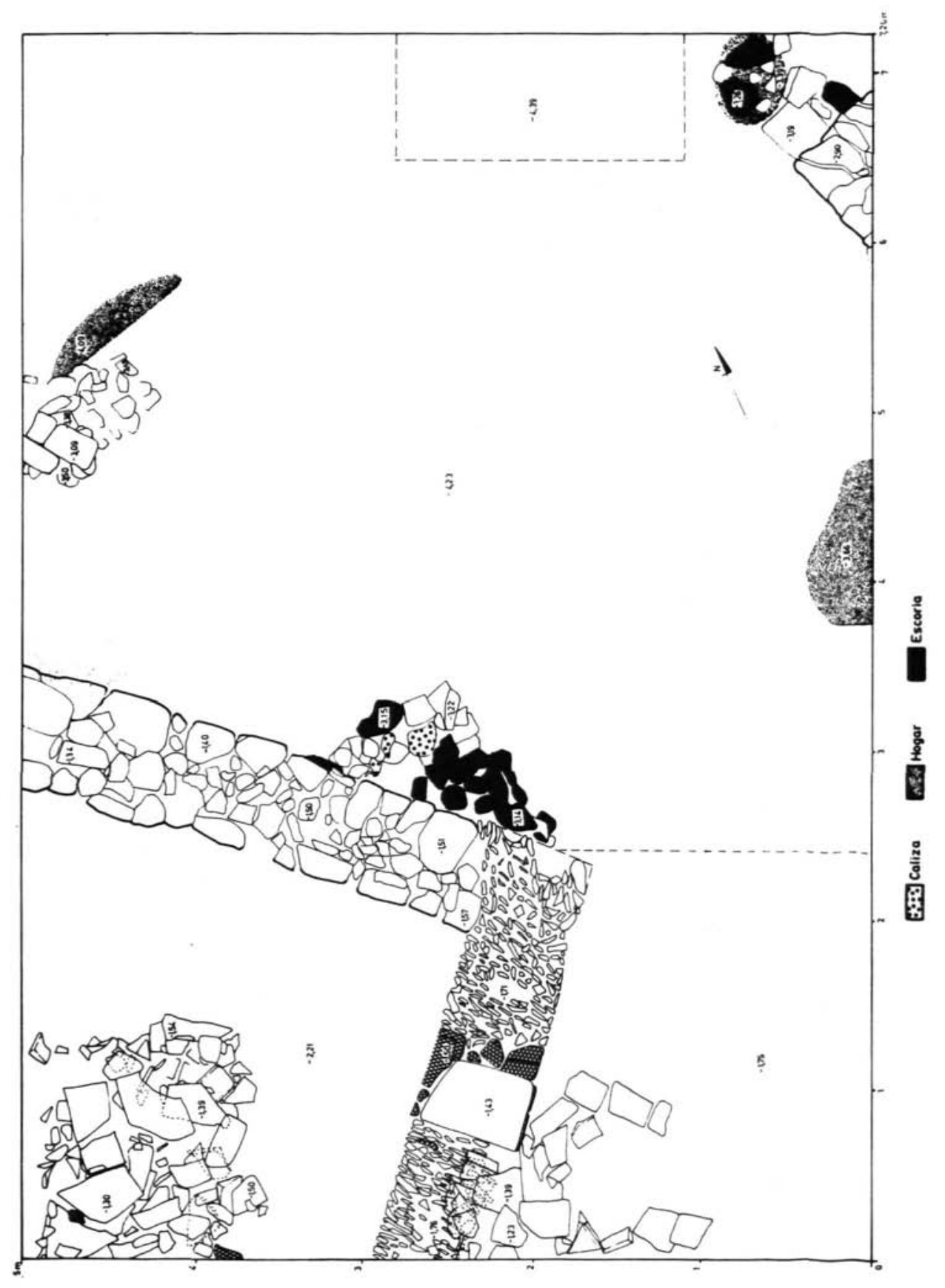

Figura 7. Habitación romana de Tres de Agosto 9-11. 


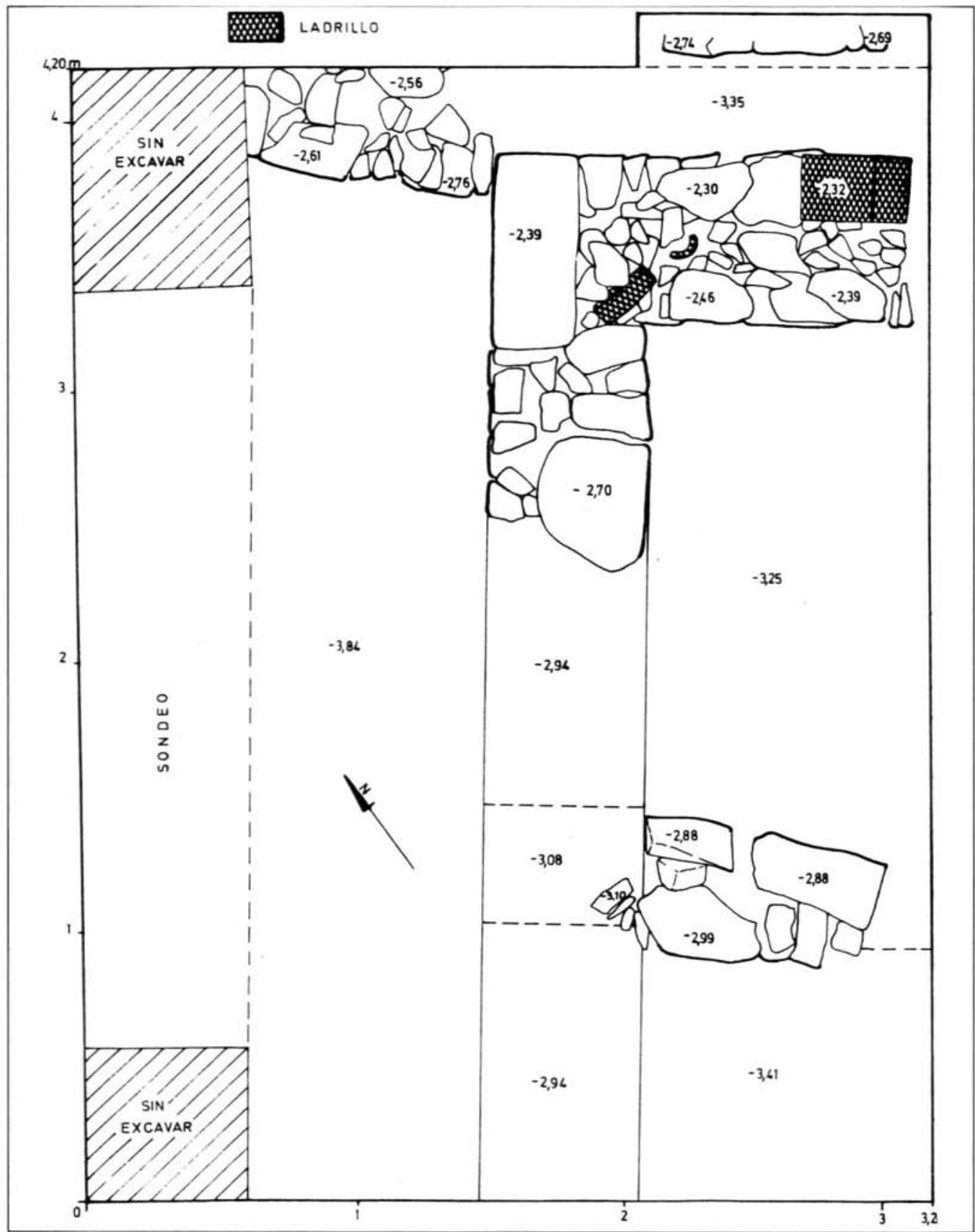

Figura 8. Planta general de Fernando el Católico 10. 
En el ángulo $\mathrm{SO}$, a $-0^{\prime} 55 \mathrm{~m}$. hallamos los restos de un muro de $0^{\prime} 60 \mathrm{~m}$. de anchura, que conservaba una potencia máxima de $1 \mathrm{~m}$. y que en la zona central había sido desmontado al hacer el desagüe de la casa que había ocupado el solar. El muro estaba realizado con piedras calizas y pizarras de mediano tamaño, mal trabajadas y dispuestas en cuatro hiladas. La más profunda estaba colocada sobre un lecho de pequeñas lajas de pizarras dispuestas verticalmente en dos capas que servían de nivelación, lo que recuerda la técnica constructiva descrita en Tres de Agosto 9-11; y sobre la superior se hallaban algunos ladrillos en el extremo occidental del muro. Para la realización del mismo se hizo una fosa de cimentación de 0'50 $\mathrm{m}$. de profundidad, en la que se embutían además de la base de nivelación, las dos hiladas inferiores.

Entre los mampuestos que formaban la base del muro se halló un fragmento de sigillata hispánica, procedente con toda probabilidad del taller de Andújar, lo que permite establecer una cronología de mediados del siglo I d.C. para la construcción de este muro.

\section{Calle Palos 12}

En Noviembre de 1990 iniciamos los trabajos arqueológicos en este solar de la calle Palos, propiedad de las Madres Agustinas. Dicho solar se unía, a través del patio, con la zona de huerta y corral del convento situado en el $n^{\circ} 4$ de la calle Tres de Agosto, colindante con la factoría excavada en Millán Astray (hoy Tres de Agosto)(fig. 1).

La excavación se localizó en la zona de huerta, abriéndose un corte de $8 \times 5 \mathrm{~m}$., al objeto de evitar los restos de cimentaciones. Igualmente se efectuó el control y supervisión en el vaciado del extremo occidental del solar, junto al corte estratigráfico, donde pudimos documentar la existencia de otras edificaciones (fig. 10)(4).

\section{Edificio de mampuestos}

En el cuadro mencionado y a una profundidad de $-2 /-2^{\prime} 10 \mathrm{~m}$. comenzó a aparecer un muro junto al perfil oriental y casi paralelo al mismo. Está realizado con pequeños mampuestos de pizarra, intercalándose entre ellos alguno de mayor tamaño, así como varios fragmentos de ladrillos. El muro tiene una anchura de $0^{\prime} 80 \mathrm{~m}$. y conserva una altura de 2' $10 \mathrm{~m}$., estando la mitad inferior realizada con piedras de mayor tamaño.

Este muro tiene adosado, por el lado oriental, otros dos más estrechos, de 0'60 m., que dejan un espacio entre ambos de 1'20 m. Ambas estructuras penetran en el perfil y al vaciarse la zona aneja al cuadro hemos podido documentar la construcción de la que estos muros formaban parte.

El edificio se compone de un compartimento alargado de 4'5x1'20 m. y junto a él otra estancia cuadrada de mayores dimensiones $\left(5 \times 4^{\prime} 5 \mathrm{~m}\right.$.), mientras que hacia el Este encontramos

(3) Las direcciones de muros (M) reflejadas en la figura 9, corresponden a diversos niveles de habitación del complejo urbanismo protohistórico de Huelva.

(4) En el momento de redactar el presente trabajo, nos encontramos a la espera de que la Dirección General de Bienes Culturales de la Junta de Andalucía, nos autorice continuar la excavación en las zonas destinadas a uso polideportivo, huerta y jardín, cuya finalidad es documentar y recuperar el edificio público allí existente, así como la trama urbana que le acompaña, como queda de manifiesto en lo hasta ahora excavado. 


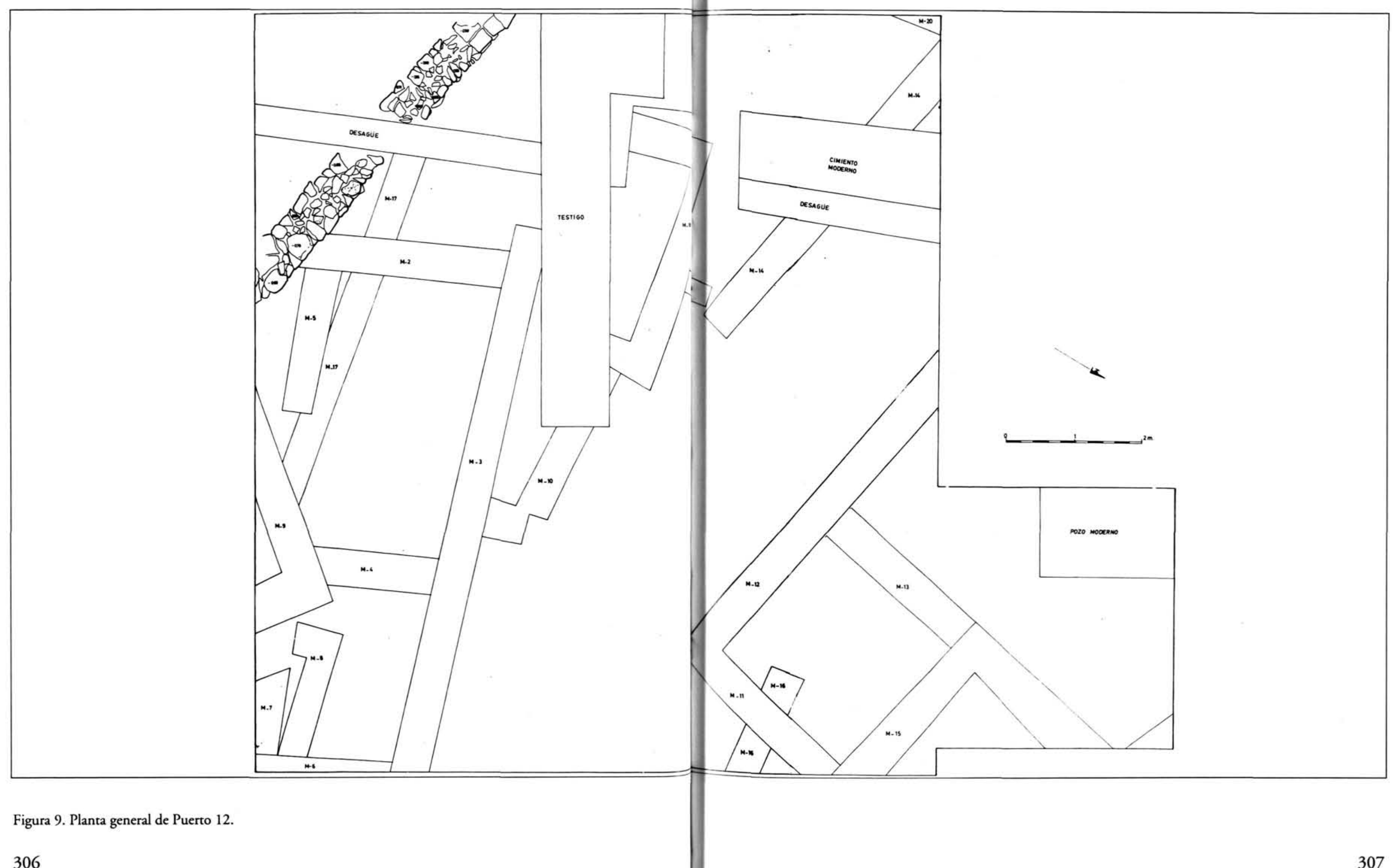


otras dos estancias gemelas separadas por un espacio alargado de $2^{\prime} 10 \times 7 \mathrm{~m}$. al que se accede por el sur.

Al primer muro citado se le une en el extremo sur y por el lado occidental otro, también de mampuestos y de la misma anchura, aunque aparece a una cota de -2'60 m.; conservan una altura de 1'30 m. y poseen similares características que el anterior, aunque con una técnica constructiva más cuidada, ya que la cara externa de las pizarras está muy bien cortada y se han rellenado con pequeños ripios los espacios dejados entre las pizarras mayores.

\section{Edificio de Sillares}

En el ángulo Noroeste del cuadro y a la cota de $-2^{\prime} 47 \mathrm{~m}$. comenzó a aparecer la esquina de un edificio, formado por grandes sillares de arenisca con dimensiones de 0'60x0'60x1'20 m. De él se conservan tres hiladas que apoyan en un amplio cimiento, realizado con cascotes y piedras ligados con mortero de cal, que alcanza una potencia de casi 0'90 m. El edificio conserva una altura de 1'60 m. en la fachada sur, con tres hiladas de sillares, mientras que en el lado oriental tan sólo se conserva la hilada de base. Sobre la primera hilada, cuya cara exterior no está bien trabajada, se levantan otras dos, estando los sillares moldurados y no quedando restos de la parte superior de la estructura (fig. 11).

En relación con esta construcción debemos poner un poyete que parece rodear el edificio, dejando una separación de 2'80 m. por el lado sur, mientras que por la parte oriental tan sólo hay una distancia de 1'20 m. Este murete, cuyos restos aparecen a la cota de -3'18 m., conserva una altura de 0'50 m., siendo esta misma su anchura. Está realizado con tégulas superpuestas con la pestaña hacia arriba, rellenándose el espacio entre las mismas con mortero de cal. La cara que da al edificio se recubre con una gruesa capa de opus, que posiblemente también cubriría la parte superior, pero de lo que apenas quedan restos.

Como ya hemos mencionado, esta estructura hay que ponerla en relación con el edificio de sillares, ya que el revestimiento de opus continuaba como suelo y llegaba hasta la base de la segunda hilada moldurada, por lo que en el momento de la utilización conjunta de ambas construcciones la hilada de sillares más profunda debió estar cubierta.

Para datar provisionalmente este conjunto contamos con una serie de elementos, entre los que hemos de destacar una lucerna decorada con esfinge, perteneciente a la forma Dressel $9 \mathrm{~b}$ (Beltrán, 1990, 264, 1133)(fig. 13, 5) hallada en el estrato que cubre la hilada más profunda del edificio. Este tipo de lucerna se inicia en época de Augusto, aunque será con los Flavios cuando alcancen una mayor difusión y comiencen las producciones locales; sin embargo, por la arcilla y lo esmerado de la decoración, parece corresponder más a una producción itálica fechable a mediados del siglo I d.C.

Hemos hallado igualmente dos fragmentos de sigillata marmorata, uno de ellos en el nivel que cubre los sillares moldurados (fig. 13, 4), en un estrato muy potente con abundantes cascotes y restos cerámicos, que debemos poner en relación con el momento de abandono de este edificio y por tanto fecharlo en el tercer cuarto del siglo I d.C.

Por último y fuera del cuadro excavado, en la limpieza de los muros del edificio antes descrito, apareció una moneda de cobre en la que se reconoce, en el anverso, una cabeza laureada mirando a la derecha, con leyenda que parece aludir a Trajano, pero su mal estado de conservación nos impide hacer mayores precisiones. 


\section{Calle Palos 23}

En Febrero de 1991 iniciamos los trabajos arqueológicos en este solar de la calle Palos. El hallazgo de pilas de salazones en el solar colindante (Palos 21)(fig. 1), a la que ya nos hemos referido, hacia presumible la existencia de restos arqueológicos en él, como así hemos podido comprobar.

Montamos un cuadro de $5 \times 7 \mathrm{~m}$. dividido en dos sectores, utilizando para ello los restos de un muro de cimentación de la casa que ocupaba con anterioridad el solar (fig. 12). Esta estructura estaba colocada justo encima de un muro romano que aparecía a una profundidad de 0'17 m. y alcanzaba hasta -1'10 m. El muro se levantaba sobre una base de pizarras de pequeño tamaño que servía de nivelación y sobre ella se disponían tres hiladas de este mismo material, pero de mediano y gran tamaño, intercalándose entre ellas algunos fragmentos de ladrillo. Por encima, el muro cambiaba de aspecto y las dos hiladas superiores las formaban piedras de mayor tamaño, dejando entre ellas un hueco de 0'50 m. que se rellenaba con ladrillos, a modo de pilar. Este esquema se repetía en otras zonas del muro, dejando una separación entre los ladrillos de 1'90 m.

Asociado a este muro había otros dos que formaban ángulo con él, delimitando así un espacio de $3 \mathrm{~m}$. de anchura, sin que podamos precisar la longitud que tendría, ya que uno de los muros estaba desmontado en un extremo y el otro continuaba bajo el perfil. Ambos estaban realizados con una técnica similar al descrito, aunque no tenían la hilada de base de pequeñas piedras e incluso uno de ellos conservaba encajado en la parte superior un tramo de ladrillos.

Esta excavación finalizó en los últimos días de Abril de 1991 y los restos encontrados están en fase de catalogación; sin embargo, el hallazgo de una moneda con toda probabilidad de Claudio, asociada a estos muros, nos permite avanzar una valoración cronológica.

La moneda, que se conserva en buen estado, presenta en el anverso una cabeza masculina mirando a la derecha con el cabello rizado, acompañada por la leyenda TI --- S CAESAR AUG P M TR P IMP; en el reverso hay una figura femenina sentada con la leyenda CERES AUGUSTA SC.

La presencia de esta moneda nos permite afirmar que estamos ante construcciones realizadas a mediados del siglo I d.C. y que relacionamos con almacenes portuarios, dada la gran cantidad de fragmentos de ánforas encontrados, así como por su proximidad con las pilas de salazones halladas en el solar colindante y por el hallazgo de dos anzuelos de bronce.

\section{SINTESIS}

Aún sin ser todavía muy numerosos los restos arqueológicos de época romana hallados en Huelva, los que hoy poseemos nos permiten, al menos como hipótesis de trabajo, hacer algunas precisiones respecto de lo que supuso la presencia romana en esta ciudad.

La primera apreciación que podemos hacer es de tipo topográfico, pues se observa que, por las evidencias hasta ahora conocidas, el poblamiento romano se sitúa por debajo de la cota de 10 m., al tiempo que hemos de suponer que su extensión hacia cotas más bajas no debió ser mucha, dada la localización de las factorías (fig. 1).

Una segunda consideración es la relativa al hallazgo de zonas de poblamiento, con lo que se va completando la realidad física de ONUBA, pues hasta ahora sólo se habían documentado necrópolis y factorías de salazones. 


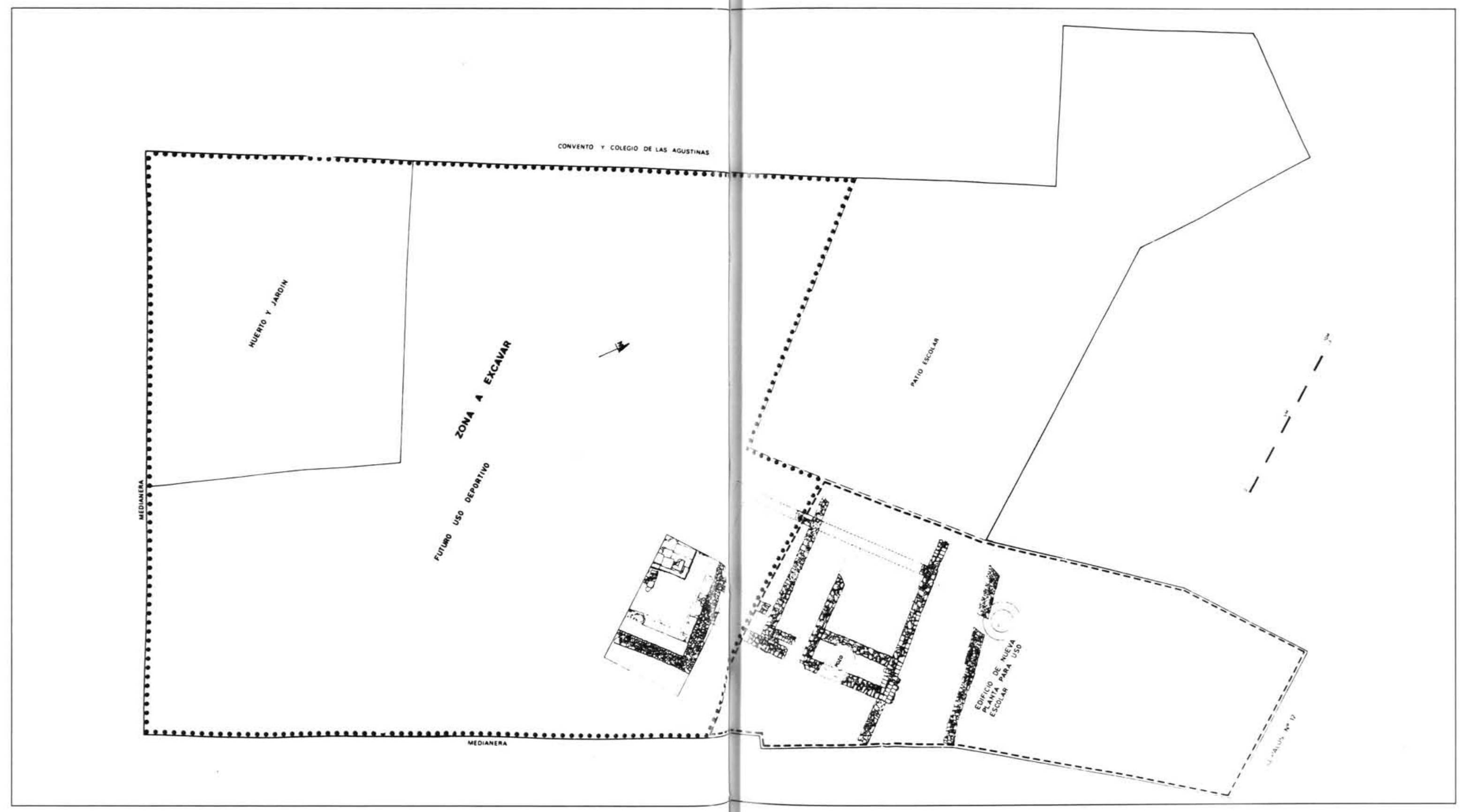

Figura 10. Planta general de Palos 12. 


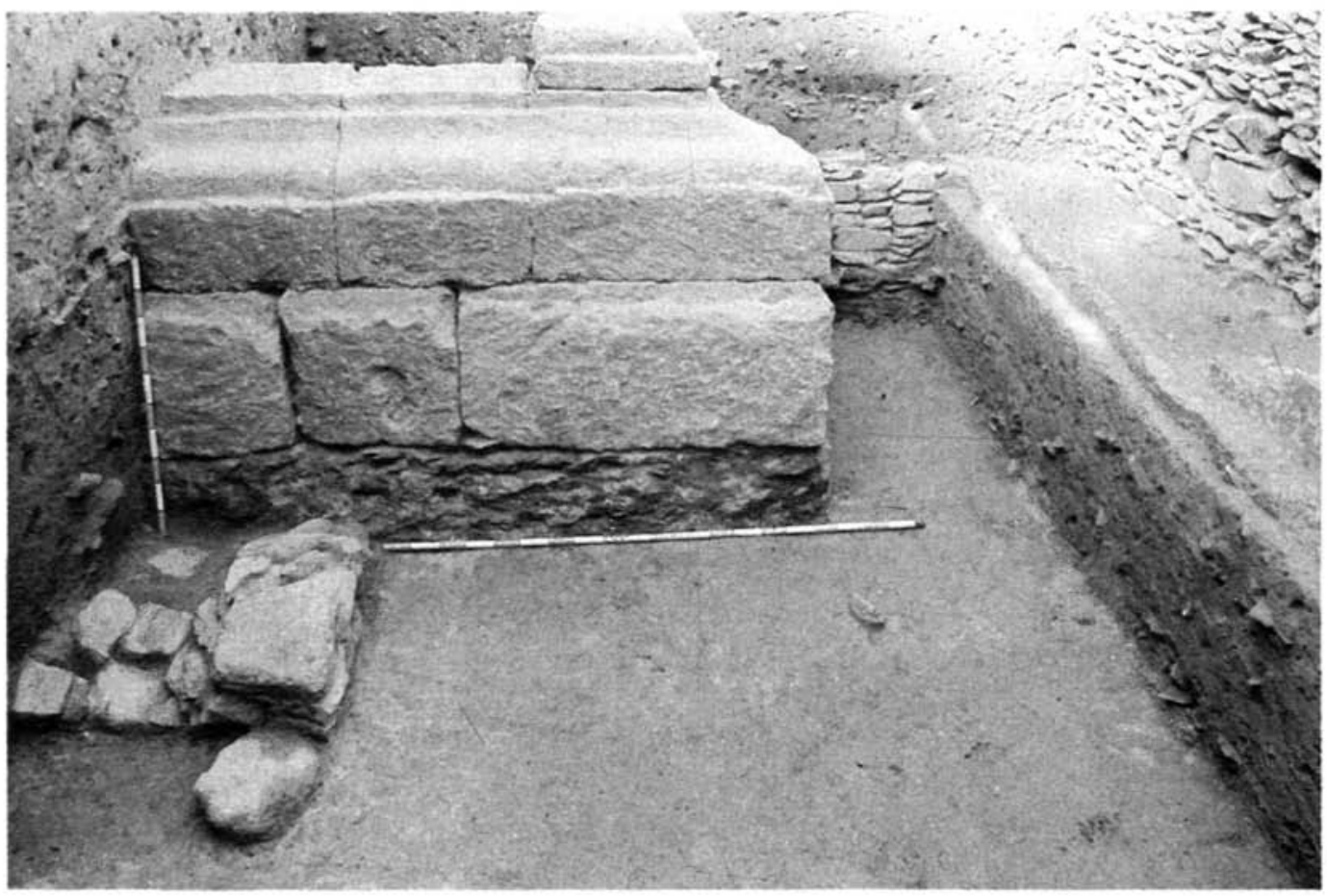

Figura 11. Edificio de sillares de Palos 12. 


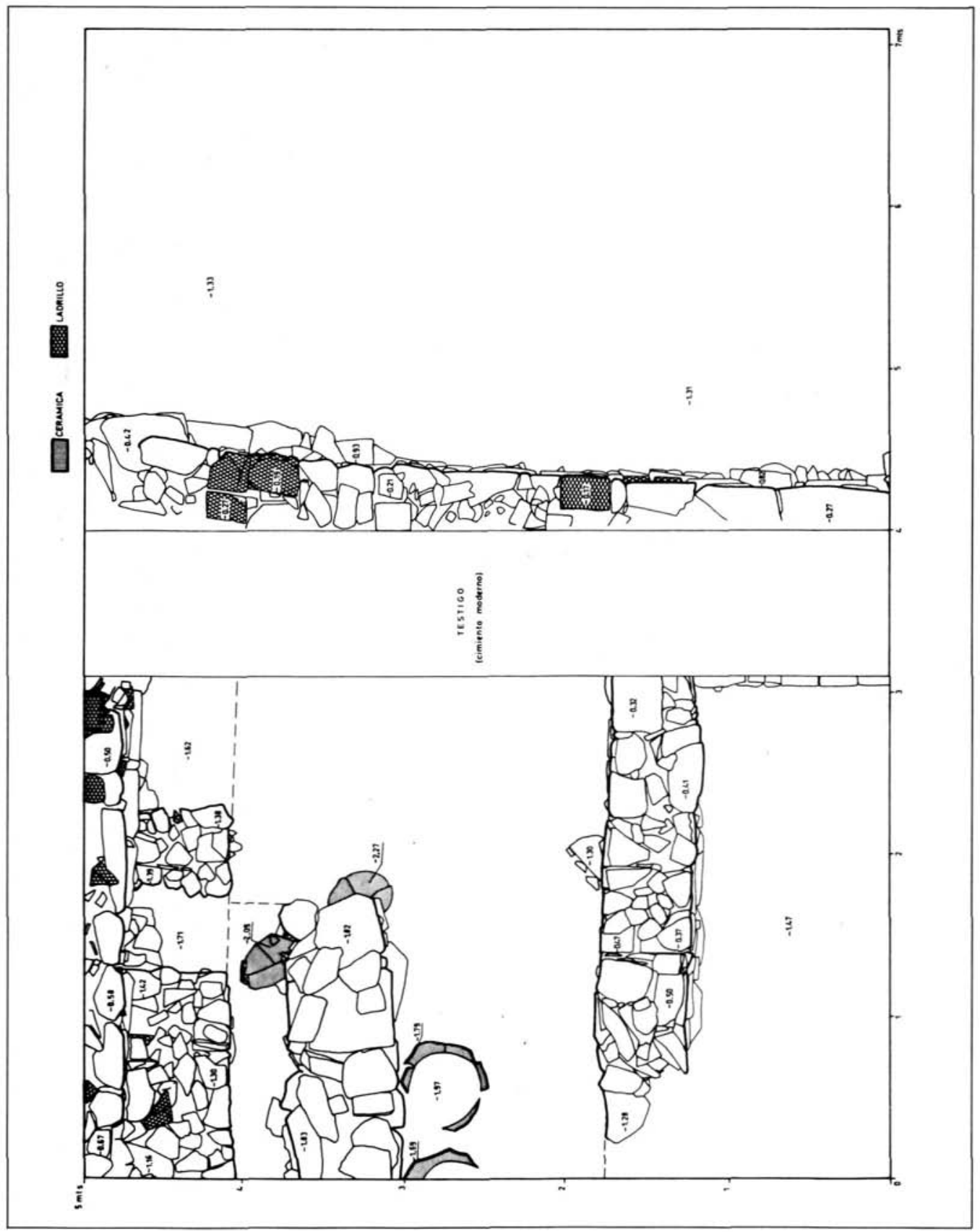

Figura 12. Planta general de Palos 23. 


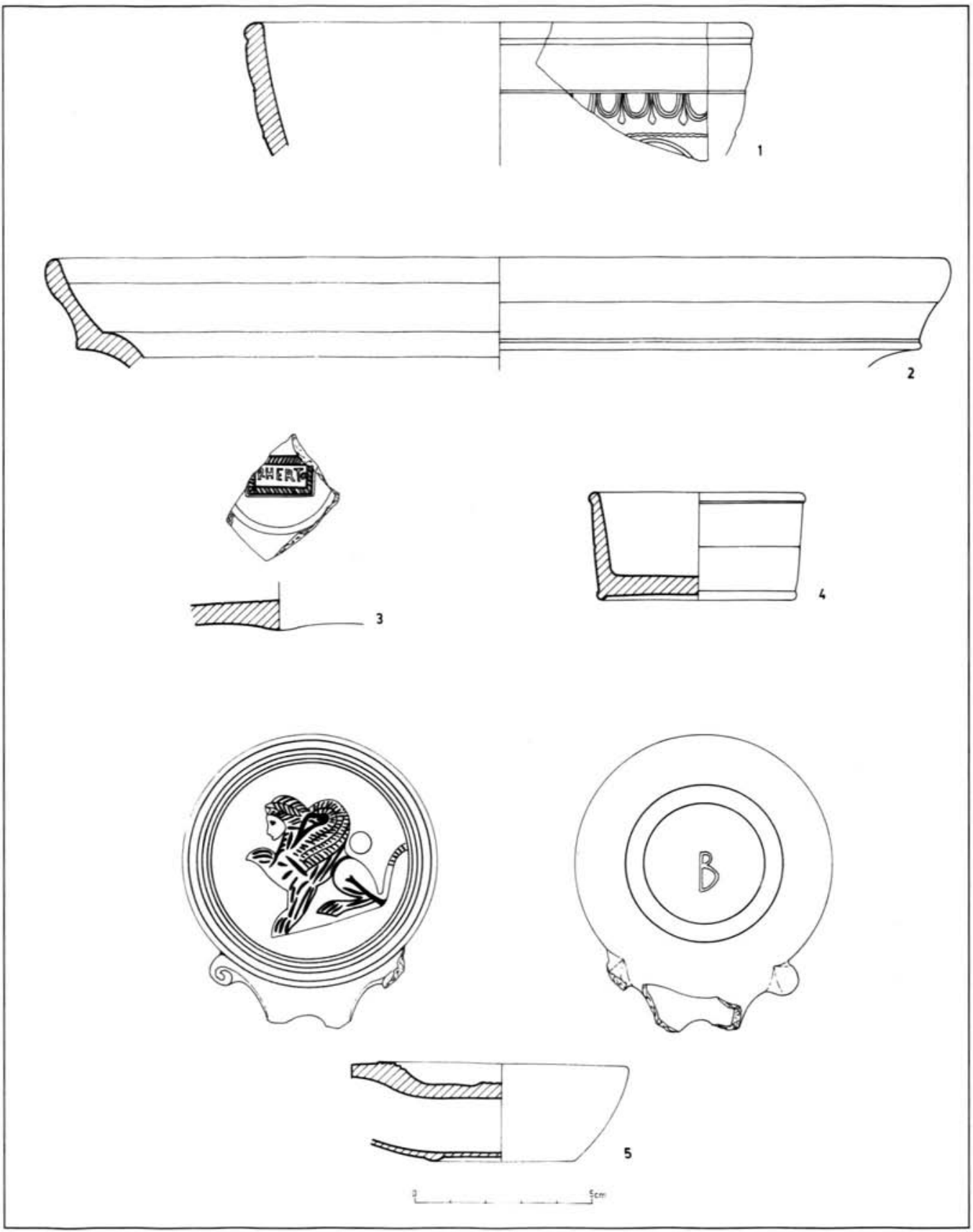

Figura 13. Cerámicas romanas de Huelva. 
Como consecuencia de lo expuesto, se comprueba que las evidencias poblacionales halladas corresponden a un periodo cronológico muy concreto, como es el que abarca desde el segundo tercio del siglo I d.C. hasta los inicios del II, con un momento álgido a mediados del siglo I, pero de no muy larga duración por la decadencia que se aprecia ya a fines del citado siglo. Esta es la población que se corresponde con la factoría de salazones de Palos 21 y con la necrópolis de La Esperanza.

A partir del inicio del siglo II d.C. nos encontramos, hasta hoy, con un amplio vacio hasta mediados del siglo III, momento a partir del cual se documenta la necrópolis de Onésimo Redondo, que estuvo en uso hasta los inicios del IV. Esta necrópolis debemos ponerla en relación con la factoría de Millán Astray, que se abandona a fines del III o comienzos del IV.

Como puede comprobarse, las evidencias romanas de Huelva corresponden a época imperial, pues ni siquiera el fragmento con el sello de P. HERTO va más allá del año 10 a.C., siendo éste el elemento de época romana más antiguo que hemos hallado.

De otra parte, la necrópolis de La Orden queda como un elemento aislado de Huelva. Desde el punto de vista urbano, dada su lejanía en dirección norte, más parece deba relacionarse con una población pequeña y cercana a Huelva. Y desde una perspectiva cronológica, también queda alejada, pues aunque parece su uso se inicia a principios del siglo IV perdura hasta el V, definiendo un periodo que, por el momento, no se documenta en la propia Huelva, de ahí la posibilidad apuntada de su pertenencia a una población distinta a ésta.

En definitiva, podemos plantear la siguiente síntesis para la presencia romana en Huelva, dejando al margen, por lo ya expuesto, la necrópolis de La Orden:

- documentación de la presencia romana desde el cambio de Era, merced a un elemento aislado y descontextualizado (P. HERTO).

- poblamiento de cierta importancia, con fundamento económico en las salazones, a partir de mediados del siglo I y hasta el inicio del II.

- vacio de evidencias durante el siglo II.

- nuevos elementos a partir de mediados del III y hasta principios del IV.

Esta síntesis poblacional y cronológica, nos permite hacer las propuestas de interpretación que recogemos en las páginas que siguen.

\section{VALORACION}

La tradición y los eruditos han defendido a Huelva como la vieja Onuba, identificación que no se ha discutido o se ha hecho sin demasiada convicción, caso del P. Flores que primero la localizaba en la cercana Gibraleón, como antes había hecho Rodrigo Caro (Caro, 1896, 748 ss.) y más tarde hizo Schulten (Schulten, 1972, 65), para posteriormente desdecirse y abogar también por su ubicación en Huelva (Amo, 1976, 15)(5).

Pero, dejando al margen estas discusiones de carácter textual e historiográfico, hemos de concluir que, en el momento actual, la arqueología va poniendo en evidencia la realidad de la roma-

(5) Nos parece innecesario hacer una exhaustiva enumeración de la bibliografía referida a esta cuestión, por considerar es suficientemente conocida; no obstante, gran parte de ella se recoge en la obra de M. del Amo que aparece en la bibliografía de este artículo. 
na Onuba en el solar de la actual Huelva. Problema distinto y aún por concretar, es saber cómo fue aquella población.

La ciudad de Huelva ha fundamentado su existencia, a través de la Historia, en las diversas posibilidades económicas que su posición costera le proporcionaba, lo que se ha venido traduciendo en un mayor o menor protagonismo, según asentara su economía en las actividades minero-metalúrgicas, que la enriquecían, o en las agropecuarias y /o pesqueras, que le permitían subsistir, pero que no generan riquezas del nivel de las minero-metalúrgicas.

Y Onuba no estuvo al margen de esta constante histórica, aunque insertada en una economía agropecuaria y pesquera. Podría preguntarse, entonces, cómo no se benefició de la masiva explotación minera que, por toda la faja pirítica de la sierra de Huelva, llevaron a cabo los romanos.

Realmente no es fácil dar una respuesta a esta interrogante, pues si bien la explotación minera de Riotinto pudo tener una salida terrestre directa hacia el ámbito Itálica-Hispalis y aprovechar luego la vía fluvial del Guadalquivir, no ocurre lo mismo con las explotaciones de Tharsis, en el ámbito occidental de la actual provincia de Huelva y cuya salida natural es doble: el río Odiel hasta Huelva o el río Guadiana hasta Ayamonte; en ninguno de los dos casos se han documentado, hasta el momento, evidencias de esta actividad económico-comercial y portuaria.

Ante esta realidad, y los datos aportados por la arqueología, parece que nos encontramos ante una Onuba agropecuaria primero y pesquera más tarde.

La Onuba agropecuaria sólo podemos deducirla a partir de las escasas monedas que de ella se conocen, las cuales portan en el reverso dos espigas. Estas monedas, que debieron emitirse con anterioridad a la prohibición de que en las provincias se acuñase, excepción hecha de algunos municipios, parecen ejemplificar un núcleo eminentemente agrícola y de no mucha relevancia, al menos por la escasez de los datos arqueológicos que conocemos.

Avanzado el siglo I, como ya hemos apuntado, Onuba inicia un discreto resurgir económico, como parecen evidenciarlo las construcciones que hemos excavado y a las que con anterioridad nos hemos referido. Este auge parece coincidir con el que en general se produce en la Bética durante época Flavia.

Ahora bien, este resurgimiento onubense, fundamentado en una economía pesquera, como evidencian las factorías de salazones, es muy coyuntural y como hemos visto apenas dura algo más de 50 años y, en nuestra opinión, debió estar vinculado al ámbito gaditano que, desde época turdetana, venía monopolizando la actividad pesquera de la costa suroccidental de la Península Ibérica.

Con posterioridad a este corto periodo de relativo crecimiento económico, Onuba parece volver a una situación precaria, como parece evidenciar la pobreza del escaso poblamiento hallado, así como de la necrópolis de momentos posteriores, es decir, el que correponde ya al siglo III.

En definitiva, Onuba parece tuvo, en general, un escaso protagonismo y sólo en la segunda mitad del siglo I fue capaz de desarrollar una producción de salazones de relativa importancia.

Huelva, Enero 1991 


\section{BIBLIOGRAFIA}

AMO, M. DEL, 1976: "Restos materiales de la población romana de Onuba". Huelva Arqueológica II. Huelva.

Beltran, M., 1990: Guía de la cerámica romana. Libros Pórtico. Zaragoza.

CARO, R., 1896: Antigüedades de Sevilla. (reimpresión 1896).

Poveda, A. y Ribera, A., 1985: "Marcas de Terra Sigillata de Elda". Sagumtum 19, 301-310. Valencia.

SChulten, A., 1972: Tartessos. Ed. Salvat. Colec. Austral n 1.471. Madrid. 